\title{
PRODUÇÃO E CARACTERIZAÇÃO DE PROTEASE OBTIDA POR Gliocladium verticilloides ATRAVÉS DA FERMENTAÇÃO EM ESTADO SÓLIDO DE SUBPRODUTOS AGROINDUSTRIAIS
}

\section{PRODUCTION AND CHARACTERIZATION OF PROTEASE FROM Gliocladium verticilloides BY SOLID-STATE FERMENTATION OF AGROINDUSTRIAL WASTES}

\author{
Gislaine A. B. da Silva ${ }^{1}$; Wallynson E. S. Almeida ${ }^{1}$, Monica S. Cortes ${ }^{1}$, Eduardo S. Martins ${ }^{1}$. \\ ${ }^{1}$ Universidade do Estado de Minas Gerais (UEMG), Frutal - MG / Brasil \\ edusmartins@yahoo.com.br
}

\begin{abstract}
Resumo
Recentemente, vários subprodutos agroindustriais têm sido usados como substratos para a produção de enzimas, devido à disponibilidade local e por representar uma fonte alternativa de baixo valor comercial, principalmente quando se visa a produção em larga escala. As proteases microbianas representam aproximadamente 60\% das vendas mundiais de enzimas, tendo aplicação no processamento de alimentos e bebidas, formulação de detergentes, produção de medicamentos, dentre outras. Na área de alimentos, uma aplicação está no processo de coagulação enzimática do leite, no processo de produção de alguns tipos de queijo. No presente trabalho, foi analisada a produção, caracterização e potencial de aplicação de proteases produzidas pelo fungo Gliocladium verticilloides, através de fermentação em estado sólido de diferentes subprodutos agroindustriais. Observou-se que o melhor substrato para a produção da protease foi o farelo de trigo, após 2 dias de fermentação. $O$ extrato enzimático obtido foi caracterizado, apresentando 3 picos de pH ótimo (5,5, 6,5 e 8,0) e temperatura ótima na faixa entre $60-65{ }^{\circ} \mathrm{C}$. O extrato enzimático mostrou-se estável até $60^{\circ} \mathrm{C}$, e manteve mais de $80 \%$ da atividade na faixa de $\mathrm{pH}$ entre 4,0 e 10,0, nas condições testadas. $O$ mesmo mostrou potencial para aplicação no processo de coagulação do leite.
\end{abstract}

Palavras-chave: fermentação em estado sólido; subprodutos agroindustriais; protease; coagulação; Gliocladium verticiloides.

\section{Introdução}

As proteases representam cerca de $60 \%$ do mercado industrial de enzimas, sendo extensamente usadas na indústria de detergentes, de cerveja, de couro, farmacêutica e alimentícia como na coagulação do leite para produção de queijos, agente hidrolítico na maturação de queijos, tenderização de carnes, panificação, etc. Proteases microbianas, principalmente fúngicas, 
apresentam vantagens como fácil obtenção e recuperação (KUMAR et al., 2005).

Recentemente, muitos estudos estão sendo feitos visando a obtenção de destas enzimas, como de Thermomyces lanuginosus (JENSEN et al., 2002; LI et al., 1997), Aspergillus (CORAL et al., 2003; SHATA, 2005; TUNGA et al., 2003), Penicillium (GERMANO et al., 2003; HASHEM, 2000), Mucor (MAHESHWARI et al., 2000; TUBESHA E AL-DELAIMY, 2003) e Rhizopus oryzae (KUMAR et al., 2005).

Diversos subprodutos agro-industriais têm sido usados como substratos para a produção de enzimas, devido à disponibilidade local e por representar uma fonte alternativa de baixo valor comercial (MARTINS et al., 2002; MARTINS et al., 2007; SILVA et al.; 2005). Assim, pode-se, com seu aproveitamento, agregar valor a estes produtos e reduzir custos de produção das enzimas.

No processo de coagulação do leite para obtenção de queijo, a escolha do agente coagulante é fundamental, pois ao lado de enzimas produzidas por bactérias, láticas ou não, as enzimas do agente coagulante influenciam na degradação protéica, sendo umas mais proteolíticas que outras (FOX et al., 1991). A pepsina bovina, por exemplo, é uma das mais proteolíticas, é menos específica que a quimosina e pode hidrolisar excessivamente as caseínas, contribuindo com a diminuição do rendimento e promovendo sabor amargo ao produto, além de causar redução na vidaútil do queijo (FOX, 1997).

O coalho bovino ainda é o mais utilizado no processamento de queijos, entretanto algumas pesquisas estão sendo desenvolvidas com o objetivo de comparar a influência dos diferentes tipos de agentes coagulantes, exercida sobre os parâmetros físico-químicos e sobre o rendimento de alguns tipos de queijos (BARBANO et al., 1992;). Um extrato enzimático com poder coagulante do leite já produzido industrialmente é o proveniente do fungo Aspergillus niger var. awamori (NEVES-SOUZA, 2005). No entanto, a pesquisa por novas linhagens microbianas produtoras destas enzimas pode ser interessante do ponto de vista de sua aplicação industrial, na obtenção de enzimas com alto poder coagulante e com características físico-químicas adequadas. Assim, o objetivo deste trabalho foi avaliar a produção, caracterização e o potencial de aplicação no processo de coagulação do leite de proteases obtidas pelo fungo Gliocladium verticiloides, com o aproveitamento de subprodutos agro-industriais como substratos. 


\section{Material e Métodos}

\subsection{Seleção do microrganismo}

\subsubsection{Meio de cultura}

Foi utilizado um meio nutriente adaptado de Jensen et al. (2002)): 0,5\% glicerol, 2\% caseína, $0,3 \%$ de extrato de levedura, $0,5 \% \mathrm{NaCl}, 0,5 \% \mathrm{CaCO}_{3}, 0,1 \% \mathrm{~K}_{2} \mathrm{SO}_{4}, 0,02 \% \mathrm{MgCl}_{2}, 0,3 \%$ $\mathrm{K}_{2} \mathrm{HPO}_{4}$ e $0,5 \%$ de solução de elementos traços $\left(2,2 \%\right.$ de $\mathrm{ZnSO}_{4} .7 \mathrm{H}_{2} \mathrm{O} ; 1,1 \%$ de $\mathrm{H}_{3} \mathrm{BO}_{3} ; 0,5 \%$ de $\mathrm{MnCl}_{2} .4 \mathrm{H}_{2} \mathrm{O} 0,5 \%$ de $\mathrm{FeSO}_{4} .7 \mathrm{H}_{2} \mathrm{O} ; 0,16 \%$ de $\mathrm{CoCl}_{2} .5 \mathrm{H}_{2} \mathrm{O} ; 0,16 \%$ de $\mathrm{CuSO}_{4} .5 \mathrm{H}_{2} \mathrm{O} ; 5 \%$ de EDTA). Ainda foram adicionados os antibióticos ampicilina $30 \mu \mathrm{g} / \mu \mathrm{L}$ e cloranfenicol $25 \mu \mathrm{g} / \mu \mathrm{L}$.

\subsubsection{Meio para seleção e isolamento da linhagem}

Foi utilizado o meio nutriente descrito no item 1.1. acrescentando-se 3\% de ágar.

\subsection{Substratos para o processo fermentativo e obtenção dos extratos enzimáticos}

Para a fermentação, foram utilizados como substratos: farelo de trigo e farelo de milho, suplementados com solução de sulfato de amônio $\left(\mathrm{NH}_{4}\right)_{2} \mathrm{SO}_{4}$ e sulfato de magnésio $\mathrm{MgSO}_{4} \cdot 7 \mathrm{H}_{2} \mathrm{O}$ (ambos a $0,1 \%$ ).

A fermentação em meio sólido ocorreu em Erlenmeyers de $250 \mathrm{~mL}$, contendo $5 \mathrm{~g}$ de cada substrato. Para o inóculo no farelo de trigo, foram adicionados $13 \mathrm{~mL}$ de solução nutriente composta por $0,1 \%$ de sulfato de magnésio e $0,1 \%$ de sulfato de amônio. No farelo de milho, foram adicionados $6 \mathrm{~mL}$ da mesma solução, a qual contém cerca $0,5 \mathrm{mg}$ de massa micelial $/ \mathrm{mL}$.

Após cada período de 24 horas de fermentação, foram adicionados $40 \mathrm{~mL}$ de água destilada em cada Erlenmeyer, para obtenção dos extratos enzimáticos produzidos pelo fungo. Posteriormente, os mesmos ficaram sob agitação em shaker durante 20 minutos, sendo posteriormente filtrado, utilizando papel filtro, e centrifugado a $3900 \mathrm{rpm}$ durante 20 minutos. O sobrenadante foi utilizado como extrato enzimático, para os ensaios de determinação da atividade enzimática.

Estes experimentos foram feitos em três repetições e os resultados são expressos como a média encontrada em cada dia.

\subsection{Caracterização físico-química dos extratos enzimáticos}

\subsubsection{Determinação da temperatura ótima de atuação.}

Para a determinação da temperatura ótima de atuação dos extratos enzimáticos, foi seguido o processo de determinação da atividade proteolítica usando $0,3 \mathrm{~mL}$ de solução enzimática em 
tampão acetato 50mM, pH 5,5 contendo 1\% de azo-caseína (substrato), durante 20 minutos, em temperaturas de reação que variaram entre $40^{\circ} \mathrm{C}$ a $80^{\circ} \mathrm{C}$. Após este período, foram adicionados 2,4 $\mathrm{mL}$ de ácido tricloroacético (TCA) a 10\%, para paralisar a reação. Posteriormente, o material foi centrifugado, a $4000 \mathrm{rpm}$ durante 10 minutos. Do sobrenadante, foram retirados 2,4 mL, ao qual adicionou-se 2,8 mL de $\mathrm{NaOH} 1 \mathrm{M}$. Esta solução foi então agitada e levada à leitura de absorbância a $440 \mathrm{~nm}$.

\subsubsection{Determinação do pH ótimo de atuação}

Foi usado 0,3 mL de solução enzimática nos seguintes tampões contendo $1 \%$ de azocaseína: acetato ( $\mathrm{pH}$ 5,0 a 5,5), citrato ( $\mathrm{pH} 6,0$ a 7,5), tris ( $\mathrm{pH} \mathrm{8,0} \mathrm{a} \mathrm{9,5)} \mathrm{e} \mathrm{glicina} \mathrm{(} \mathrm{pH}$ 10). A reação ocorreu durante 20 minutos, a $65^{\circ} \mathrm{C}$ (temperatura definida como ótima para o extrato enzimático). Após este período, foram adicionados 2,4 mL de ácido tricloroacético (TCA) a 10\%, para paralisar a reação. Posteriormente, o material foi centrifugado, a $4000 \mathrm{rpm}$ por 10 minutos. Do sobrenadante, foram retirados 2,4 mL, ao qual adicionou-se 2,8 mL de $\mathrm{NaOH} 1 \mathrm{M}$. Esta solução foi então agitada levada à leitura de absorbância a $440 \mathrm{~nm}$.

\subsubsection{Testes de estabilidade dos extratos enzimáticos frente a variações de temperatura}

Para a realização do teste de estabilidade à temperatura, incubou-se cada extrato enzimático durante $1 \mathrm{~h}$ a diferentes temperaturas $\left(8^{\circ} \mathrm{C}, 25^{\circ} \mathrm{C}, 35^{\circ} \mathrm{C}, 40^{\circ} \mathrm{C}, 50^{\circ} \mathrm{C}, 60^{\circ} \mathrm{C}, 65^{\circ} \mathrm{C}\right.$, $\left.70^{\circ} \mathrm{C}, 80^{\circ} \mathrm{C}\right)$. Após este período, determinou-se a atividade proteolítica residual $(\%$ de atividade comparada com a encontrada quando a enzima não era pré-incubada), em tampão citrato $\mathrm{NaOH}$ com $\mathrm{pH} 6,5, \mathrm{a} 65^{\circ} \mathrm{C}$.

\subsubsection{Teste de estabilidade dos extratos enzimáticos frente a variações de $\mathbf{p H}$}

Para a realização do teste de estabilidade ao $\mathrm{pH}$, incubou-se $0,5 \mathrm{ml}$ de cada extrato enzimático, durante 24 horas, a $25^{\circ} \mathrm{C}$, em $05 \mathrm{~mL}$ dos seguintes tampões: acetato $\mathrm{pH} \mathrm{4,0} \mathrm{a} \mathrm{5,0,}$ citrato $\mathrm{pH}$ 5,5 a 7,0, tris $\mathrm{pH}$ 7,5 a 9,0 e glicina $\mathrm{pH}$ 9,5 a 10,5. Após esse período determinou-se a atividade proteolítica, da seguinte forma: foi usado $0,3 \mathrm{~mL}$ de solução retirada das diferentes soluções tampão, que foi adicionada em tampão citrato $50 \mathrm{mM}$, pH 6,5 contendo $1 \%$ de azo-caseína (substrato), durante 20 minutos, a $65^{\circ} \mathrm{C}$. Após este período, foram adicionados $2,4 \mathrm{~mL}$ de ácido tricloroacético (TCA) a 10\%, para paralisar a reação. Posteriormente, o material foi centrifugado, a 
$4000 \mathrm{rpm}$ durante 10 minutos. Do sobrenadante, foram retirados 2,4 $\mathrm{mL}$, ao qual adicionou-se 2,8 $\mathrm{mL}$ de $\mathrm{NaOH}$ 1M. Esta solução foi então agitada e levada à leitura de absorbância a $440 \mathrm{~nm}$.

\subsection{Determinação da atividade proteolítica}

A atividade de protease foi determinada usando $0,3 \mathrm{~mL}$ de solução enzimática em tampão MES 50mM, pH 5,5 contendo $1 \%$ de azo-caseína (substrato), durante 20 minutos, a $55^{\circ} \mathrm{C}$. Após este período, foram adicionados $2,4 \mathrm{~mL}$ de ácido tricloroacético (TCA) a 10\%, para paralisar a reação. Posteriormente, o material foi centrifugado, a $4000 \mathrm{rpm}$ por 20 minutos. Do sobrenadante, foram retirados 2,4 mL, ao qual adicionou-se $2,8 \mathrm{~mL}$ de $\mathrm{NaOH} 1 \mathrm{M}$. Esta solução foi então agitada levada à leitura de absorbância a $440 \mathrm{~nm}$.

Para o controle da reação, primeiro colocou-se o TCA (inibidor da reação), sendo posteriormente adicionada a solução enzimática. Neste, a leitura também foi feita em espectrofotômetro, a $440 \mathrm{~nm}$. Uma unidade de enzima foi definida como a quantidade de enzima encontrada na diferença de absorbância a $440 \mathrm{~nm}$ entre a amostra e o branco, por minuto de reação, sendo expressa como Unidade de enzima por grama de substrato $(\mathrm{U} / \mathrm{g})$.

\subsection{Determinação da atividade coagulante do extrato enzimático no leite}

Para fazer o teste de coagulação do leite, foram usados $5 \mathrm{~mL}$ de leite em pó, a uma concentração de $10 \%(\mathrm{p} / \mathrm{v})$, acrescentado de $\mathrm{CaCl}_{2}$ 0,01M, no qual foram adicionados $0,5 \mathrm{ml}$ de extrato enzimático. Após a adição do extrato enzimático, marcou-se o tempo necessário para início da coagulação. Este teste foi realizado a $40^{\circ} \mathrm{C}$ para todos os dias de fermentação, já que essa geralmente é a temperatura máxima utilizada em algumas queijarias para ocorrer a coagulação, sendo nesta temperatura, portanto, avaliada a atividade coagulante em todos os dias de fermentação. Isto foi testado porque o objetivo principal do projeto é obter enzimas com poder de coagulação do leite, em condições que se possa aplicá-la industrialmente. 


\section{Resultados e Discussão}

Uma linhagem do fungo Gliocladium verticiloides foi selecionada para os testes de fermentação, com os experimentos sendo feitos com farelo de trigo e farelo de milho. Os experimentos foram feitos em 3 repetições e os resultados estão expressos como a média de 3 experimentos, observando em qual dia apresentou a melhor atividade proteolítica.

\subsection{Atividade proteolítica do extrato enzimático obtido por fermentação em farelo de trigo e em farelo de milho como substratos, com sulfato de amônio e sulfato de magnésio como fonte suplementar de nutrientes}

Foram analisados os farelos de trigo e de milho como substratos da fermentação, sendo estes suplementados com solução nutriente composta por sulfato de amônia e sulfato de magnésio (ambos a 0,1\%). Através da figura 1, nota-se que a maior média de atividade proteolítica pelo fungo estudado ocorreu quando o mesmo foi cultivado no farelo de trigo $(11,6 \mathrm{U} / \mathrm{g})$, após 2 dias de fermentação, com um valor muito próximo ao obtido no $3^{\circ}$ dia. Observa-se que, após este período, a atividade enzimática decresceu. Isto sugere uma menor disponibilidade de nutrientes ou a liberação de metabólitos tóxicos (ROMERO et al., 1998).

Perfil de produção semelhante foi citado por Hamid Mukhtar (2006), na produção protease pelo fungo Penicillium chrysogenum, o qual produziu mais enzima entre o $2^{\mathrm{o}}$ e $3^{\mathrm{o}}$ dia de fermentação. 
Figura 1: Atividade proteolítica dos extratos enzimáticos obtidos por fermentação em estado sólido de diferentes substratos, suplementados com sulfato de amônio e sulfato de magnésio. - - - farelo de trigo; $-\Delta$ - farelo de milho.

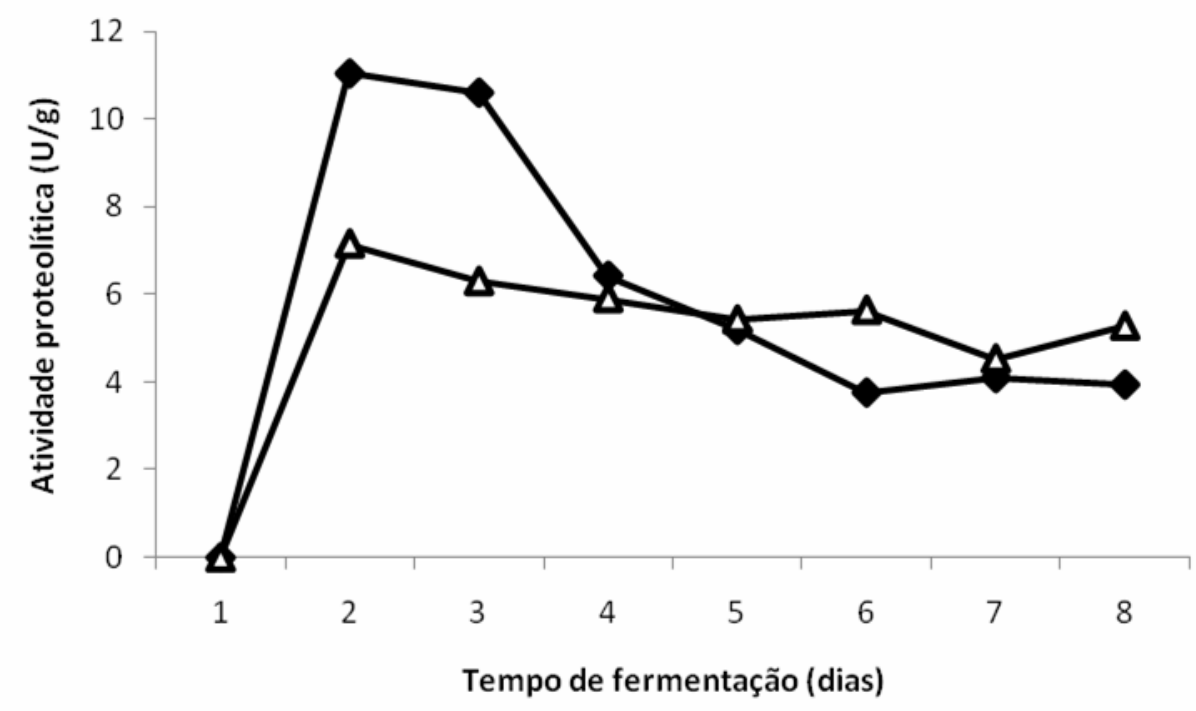

\subsection{Caracterização físico-química do extrato enzimático}

O extrato enzimático foi caracterizado com relação ao $\mathrm{pH}$ e temperatura ótimos de atuação, visando encontrar as melhores condições de reação para atividade proteolítica e avaliar a sua estabilidade frente à variações de $\mathrm{pH}$ e temperatura.

\subsubsection{Determinação da temperatura ótima de atuação proteolítica do extrato Enzimático}

Pode-se observar, através da figura 2, que a melhor temperatura para a atividade proteolítica foi entre $60^{\circ}$ e $65^{\circ} \mathrm{C}$, coma atividade de $12,7 \mathrm{U} / \mathrm{g}$, resultado semelhante ao encontrado por Merheb et al. (2007), com o fungo termofilico Thermoascus aurantiacus. Esta temperatura ótima é típica de enzimas produzidas por microrganismos termofílicos, uma vez que os mesmos se desenvolvem em temperaturas elevadas.

Para o processo de coagulação do leite, este resultado é interessante, uma vez que, a $40^{\circ} \mathrm{C}$ o extrato não apresenta alta atividade proteolítica, o que pode ser importante para não haver formação de peptídeos indesejáveis. 
Figura 2: Temperatura ótima de atuação do extrato enzimático.

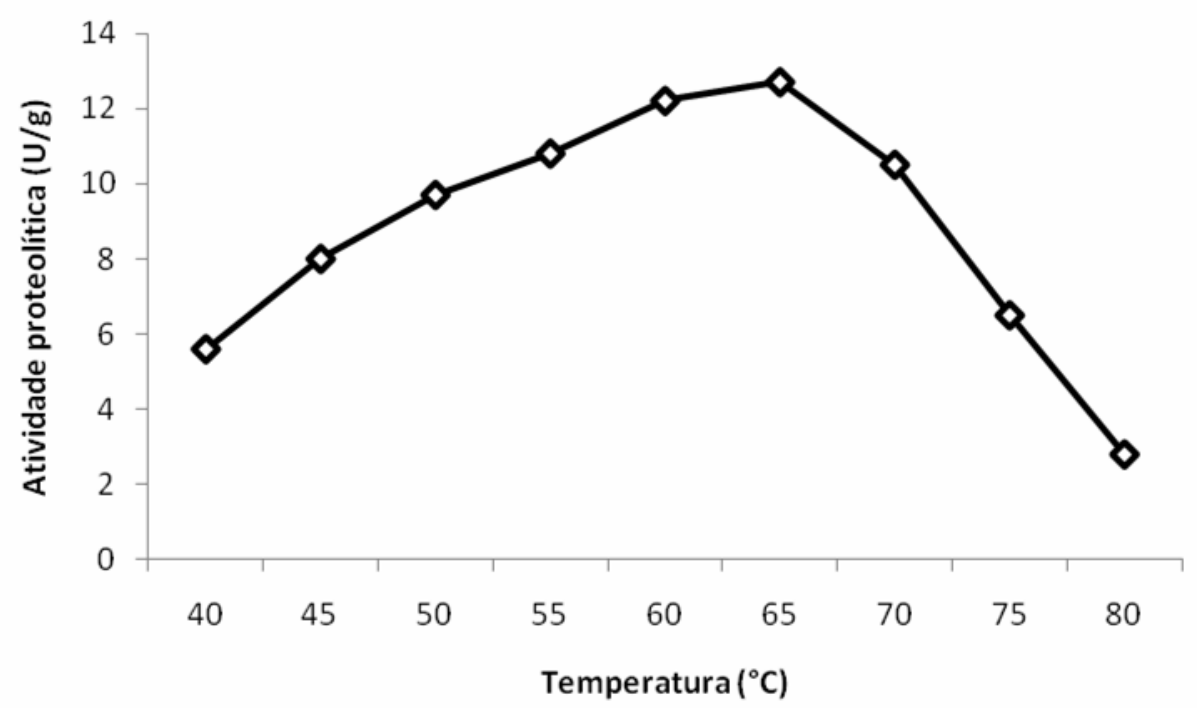

\subsubsection{Determinação do $\mathrm{pH}$ ótimo de atuação proteolítica do extrato enzimático}

Através da observação da figura 3, pode-se sugerir que existe mais de um tipo de enzima no extrato enzimático, já que existem 3 picos de atividade, em diferentes valores de $\mathrm{pH}$. No caso da possibilidade de aplicação no processo de coagulação do leite, o resultado mais interessante é o pico de atividade que ocorreu no $\mathrm{pH}$ 6,5, que é próximo ao $\mathrm{pH}$ natural do leite.

Figura 3: Influência do $\mathrm{pH}$ sobre a atividade proteolítica do extrato enzimático.

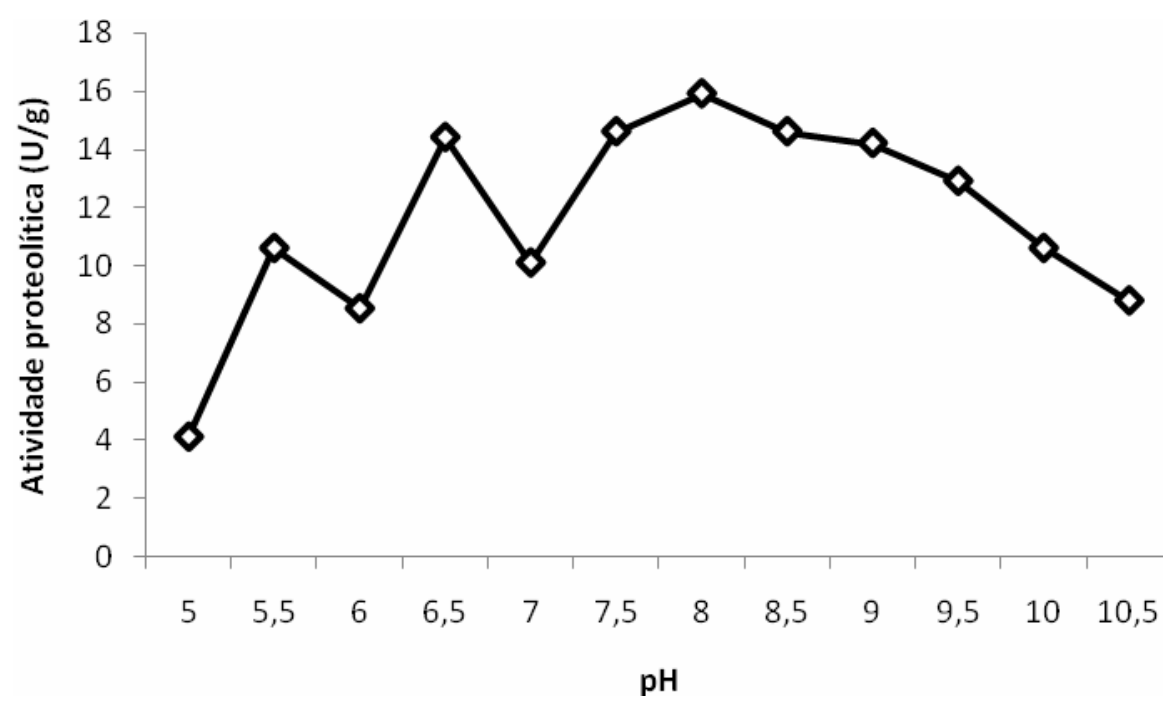




\subsubsection{Avaliação da estabilidade do extrato enzimático, frente a variações de temperatura}

Através da figura 4, pode-se observar que o extrato enzimático tem grande estabilidade a temperatura, já que mantém quase $100 \%$ de sua atividade quando mantido até $60^{\circ} \mathrm{C}$, durante 1 hora. Resultado semelhante foi relatado por Merheb et al. (2007), com o fungo Thermoascus aurantiacus.

Houve perda de atividade de forma significativa apenas quando a temperatura foi superior a $60^{\circ} \mathrm{C}$, restando cerca de $22 \%$ da atividade após incubação a $65^{\circ} \mathrm{C}$, por 1 hora e menos de $10 \%$ quando expostas a temperaturas superiores.

Figura 4: Estabilidade do extrato enzimático quando incubado por 1 hora, em diferentes temperaturas.

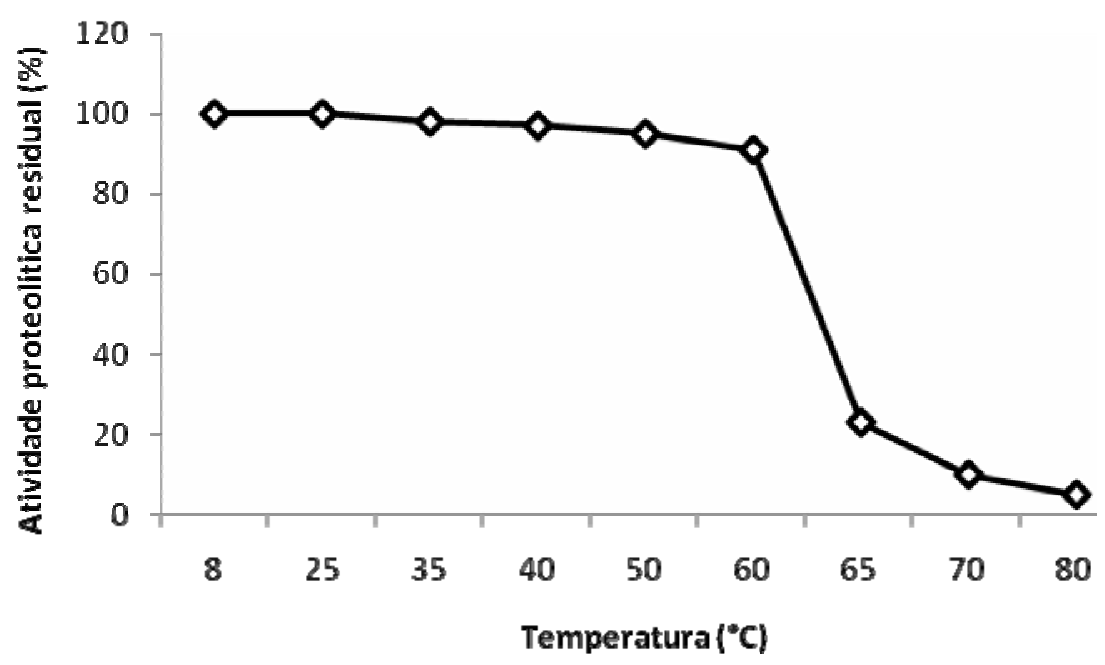

\subsubsection{Estabilidade do extrato enzimático, frente a variações de pH}

Através da figura 5, pode-se determinar que o extrato tem grande estabilidade a variações de $\mathrm{pH}$, pois todas as amostras apresentaram atividade proteolítica residual maior do que $80 \%$, apresentando atividade de $100 \%$ no $\mathrm{pH}$ de 6,5. Este resultado pode ser interessante do ponto de vista da sua aplicação, uma vez que na faixa de $\mathrm{pH}$ natural do leite o extrato enzimático mostrou-se muito estável. 
Figura 5: Estabilidade do extrato enzimático a variações de $\mathrm{pH}$, quando incubados em diferentes tampões sem substrato, durante $24 \mathrm{~h}$.

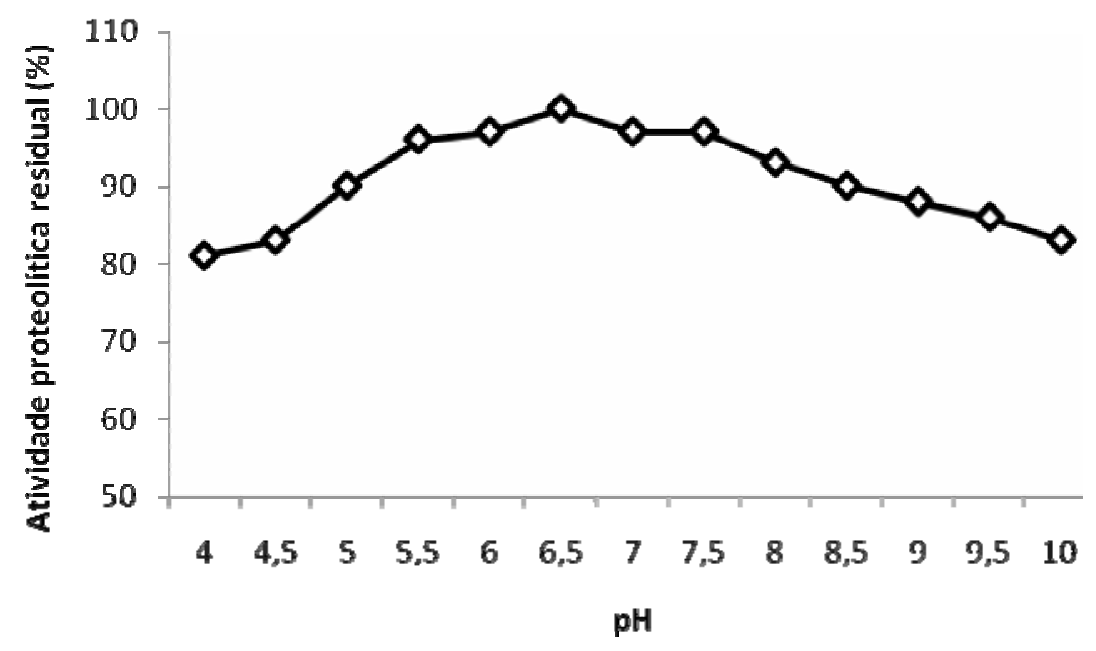

\subsection{Atividade coagulante do extrato enzimático, a $40^{\circ} \mathrm{C}$}

Uma das aplicações de proteases, na área de alimentos, encontra-se no processo de coagulação enzimática do leite, para produção de queijos. Como este processo ocorre geralmente entre $35^{\circ} \mathrm{C}$ e $40^{\circ} \mathrm{C}$, esta última foi a temperatura escolhida para fazer o teste de coagulação do leite, no presente trabalho. Observou-se que o melhor dia para a produção de extrato enzimático com ação coagulante foi o $2^{\circ}$ dia de fermentação, com 16,0 UAC, sendo que após o $4^{\circ}$ dia não houve quantidade significativa de atividade coagulante (Tab. 1).

Além disso, pode ser observado que o maior valor entre atividade coagulante/atividade proteolítica também ocorreu no $2^{\circ}$ dia de fermentação (Tab. 1), sendo, portanto, este tempo de cultivo considerado o ideal para a obtenção do extrato enzimático, para o processo de coagulação do leite. Assim, o fato de o melhor resultado entre atividade coagulante/atividade proteolítica ocorrer em apenas 2 dias de fermentação do fungo é, como dito anteriormente, interessante para possível aplicação do extrato enzimático obtido, uma vez que os custos para obtenção do mesmo diminui, por não ser um longo período de fermentação. 
Tabela 1: Relação entre atividade coagulante/atividade proteolítica do extrato enzimático produzido por Gliocladium verticiloides, em farelo de trigo.

\begin{tabular}{|c|c|c|c|}
\hline \multirow{2}{*}{ Dermentação } & Unidade de atividade & Unidade de & Valor da relação atividade \\
& coagulante (UAC) & atividade & $\begin{array}{c}\text { poagulante/atividade } \\
\text { proteolítica } \\
\text { proteolítica }\end{array}$ \\
\hline $2^{\circ}$ & 16,0 & 2,6 & 6,1 \\
\hline $3^{\circ}$ & 14,8 & 4,1 & 3,6 \\
\hline $4^{\circ}$ & 6,2 & 3,3 & $*$ \\
\hline $5^{\circ}$ & $*$ & 1,8 & $*$ \\
\hline $6^{\circ}$ & $*$ & 2,1 & $*$ \\
\hline $7^{\circ}$ & $*$ & 1,7 & $*$ \\
\hline $8^{\circ}$ & $*$ & 1,3 & $*$ \\
\hline
\end{tabular}

* quantidades não significativas.

\section{Conclusão}

Os subprodutos agro-industriais analisados mostraram-se eficientes como substratos para a produção de proteases pela linhagem fúngica estudada, proporcionando boa atividade proteolítica, além de boa atividade no processo de coagulação do leite. O extrato enzimático obtido do $2^{\underline{0}}$ dia de apresentou a maior relação entre atividade coagulante/atividade proteolítica, sendo este então considerado mais adequado para aplicação. Os resultados obtidos demonstram também a produção de um extrato enzimático com atividade proteolítica que tem potencial de aplicação em diferentes processos, uma vez que houve boa atividade enzimática em diferentes valores de $\mathrm{pH}$ e temperatura, bem como uma boa estabilidade a estes fatores.

\section{Agradecimentos}

Os autores agradecem a Universidade do Estado de Minas Gerais (UEMG - campus de Frutal) e a Fundação de Amparo à Pesquisa do Estado de Minas Gerais (FAPEMIG) pelas bolsas 
concedidas através dos Programas de Apoio à Pesquisa (PAPq/UEMG/ESTADO e PAPq/UEMG/FAPEMIG).

\begin{abstract}
Recently, several agro-industrial wastes have been used as substrates for the production of enzymes, due to local availability and represent an alternative source of low commercial value, especially when aimed at large-scale production. The microbial proteases represent $60 \%$ of worldwide sales of enzymes, with application in food and beverage processing, formulation of detergents, production of medicines, among others. In the area of food, an application is in the process of enzymatic coagulation of milk in the production process of some types of cheese. In this study, we analyzed the production, characterization and potential application of proteases produced by the fungus Gliocladium verticilloides through solid state fermentation of various agroindustrial by-products. It was observed that the best substrate for production of protease was wheat bran, after 2 days of fermentation. The enzyme extract obtained was characterized, showing 3 peaks of optimum $\mathrm{pH}\left(5.5,6.5\right.$ and 8.0) and temperatures ranging between $60-65^{\circ} \mathrm{C}$. The enzyme extract was shown to be stable to $60^{\circ} \mathrm{C}$ and maintained over $80 \%$ of activity in the $\mathrm{pH}$ range between 4.0 and 10.0, under the conditions tested. It has potential for application in the coagulation of milk.
\end{abstract}

Keywords: solid state fermentation, agro-industrial by-products; protease, coagulation; Gliocladium verticilloides.

\title{
6. Referências Bibliográficas
}

BARBANO, D. H; RASMUSSEN, R. R. Cheese yield performance of fermentation-produced chymosin and other milk coagulants. J. Dairy Sci., Champaign, v. 75, n. 1, p. 1-2, 1992.

CORAL, G.; ARIKAN, B.; UNALDI, M. N.; GUVENMEZ, H. Thermostable alkaline protease produced by an Aspergillus niger strain. Annals of Microbiology, v. 4, p. 491-498, 2003.

GERMANO, S.; PANDEY, A.; OSAKU, C. A.; ROCHA, S. N.; SOCCOL, C. R. (2003). Characterization and stability of protease from Penicillium sp. produced by solid-state fermentation. Enzyme and Microbial Technology, v. 32 , p.246-251, 2003.

FOX. P. F. Advanced dairy chemistry: proteins. London: Blackie Academic \& Professional, 1997. v. 1.

FOX. P. F.; LAW, J. Enzimology of cheese ripening. Food Biotech., v. 5, n. 3, p. 239-262, 1991.

IKRAM-UL-HAQ, HAMID MUKHTAR1 AND HINA UMBER. Production of Protease by Penicillium chrysogenum Through Optimization of Environmental Conditions. Journal of Agriculture \& Social Sciences, v. 2, p. 23-25, 2006. 
HASHEM, A. M. Purification and properties of a milk-clotting enzymes produced by Penicillium oxalicum. Bioresource Technology, v. 75, p. 219-222, 2000

JENSEN, B.; NEBELONG, P.; OLSEN, J.; REELEY, M. Enzymes production in continuous cultivation by the thermophilic fungus, Thermomyces lanuginosus. Biotechnology Letters, v. 1, p.41-45, 2002.

KUMAR, S.; SHARMA, N. S.; SAHARAM, M. R.; SINGH, R. Extracellular acid protease from Rhizopus oryzae: purification and characterization. Process Biochemistry, 2005.

LI, D. C.; YANG, Y. J.; SHEN, C.Y. Protease production by the thermophilic fungus Thermomyces lanuginosus. Mycology Researches, v. 1, p.18-22, 1997.

MAHESHWARI, R.; BHARADWAJ, G.; BHAT, M. K. Thermophilic Fungi: their physiology and enzymes. Microbiology and Molecular Biology Reviews, v. 3, p. 461-488.2000

MARTINS, E. S., Silva, D., LEITE, R. S. R., Gomes, E., da Silva, R. Purification and characterization of polygalacturonase produced by thermophilic Thermoascus aurantiacus 179-5 in submerged fermentation. Antonie van Leeuwenhoek International ., v.91, p.291 - 299, 2007.

MARTINS, E. S., Silva, D., da Silva, R., Gomes, E. Solid state production of thermostable pectinases from thermophilic Thermoascus aurantiacus. Process Biochemistry. , v.37, .949 - 954, 2002.

MERHEB, C.; CABRAL, H.; GOMES, E.; SILVA, R. Partial characterization of protease from a thermophilic fungus, Thermoascus aurantiacus, and its hydrolytic activity on bovine casein. Food Chemistry, v. 104, p. 127-131, 2007.

NEVES-SOUZA. R. D.; SILVA. R. S. S. F.; Estudo de Custo-Rendimento do Processamento de Queijos Tipo Minas Frescal com Derivado de Soja e Diferentes Agentes Coagulantes. Ciência e Tecnologia de Alimentos. Campinas. v. 25 (1); p. 170-174, 2005.

ROMERO, F., L.A. GARCIA AND M. DIAZ. Protease production from whey at high concentration by Serratia marcescens. Resource Environmental Biotechnoogy, v. 2, p. 93-115, 1998.

SHATA, H. M. A. Extraction of Milk-clotting Enzyme Produced by Solid State Fermentation of Aspergillus oryzae. Polish Journal of Microbiology, v. 3, p. 241-247, 2005.

SILVA, D; et al. Production of pectinase by solid-state fermentation with Penicillium viridicatum RFC3. Process Biochemistry, v. 40, p. 2885-2889, 2005.

TUBESHA, Z. A.; AL-DELAIMY, K. S. Rennin-like milk coagulant enzyme produced by a local isolate of Mucor. International Journal of Dairy Technology, v. 4, p.237-241, 2003.

TUNGA, R.; SHRIVASTAVA, B.; BANERJEE, R. Purification and characterization of a protease from solid state cultures of Aspergillus parasitucus. Process Biochemistry, v.38, p.1553-1558, 2003. 


\section{Autor para correspondência:}

Nome: Eduardo da Silva Martins

Filiação Institucional: Universidade do Estado de Minas Gerais (UEMG), campus de Frutal.

Departamento: Ciência e Tecnologia de Laticínios

Cargo: Professor/pesquisador

Titulação: Doutor em Ciências Biológicas (Microbiologia Aplicada).

Endereço para correspondência: Av. Prof. Mário Palmério, 1000, Bairro Universitário, CEP 38200000, Frutal, MG, Brasil

Telefones para contato: (34) 3423 2700; (34) 34214485

email: edusmartins@yahoo.com.br 